\title{
Valor Nutritivo e Desempenho de Coelhos Alimentados com Rações Contendo Milheto (Pennisetum glaucum (L.) R.Br)
}

\author{
Antonio Claudio Furlan ${ }^{1}$, Claudio Scapinello1, Fábio Luiz Buranelo Toral ${ }^{2}$, Haroldo Garcia de \\ Faria $^{3}$, Ivan Moreira ${ }^{1}$, Alice Eiko Murakami ${ }^{1}$, Maurício Luiz da Rosa Santolin ${ }^{2}$
}

\begin{abstract}
RESUMO - Três experimentos foram conduzidos com o objetivo de determinar o valor nutritivo e verificar o desempenho de coelhos em crescimento alimentados com rações contendo diferentes níveis de milheto. No ensaio de digestibilidade (experimento 1) foram determinados os valores nutritivos dos milhetos dos cultivares Comum, BN2 e Iapar IA 98301. Foram utilizados 40 coelhos machos da raça Nova Zelândia Branco, com idade média de 45 dias, distribuídos em um delineamento inteiramente casualizado, com 10 repetições. Em cada tratamento, os milhetos avaliados substituíram 30\% de uma ração referência. Os valores de energia digestível dos milhetos Comum, BN2 e Iapar IA 98301 foram, respectivamente, 3410, 3493 e $3505 \mathrm{kcal} / \mathrm{kg}$ de matéria natural. Nos ensaios de desempenho (experimentos 2 e 3) foram avaliadas rações contendo níveis crescentes de milheto Comum ou Iapar IA 98301 (0, 25, 50, 75 e 100\%) em substituição ao milho. Em cada ensaio foram utilizados 60 coelhos da raça Nova Zelândia Branco, sendo 30 machos e 30 fêmeas, com 40 dias de idade inicial, distribuídos em um delineamento inteiramente casualizado, com 12 repetições, sendo a unidade experimental constituída por um animal. Não foram observadas diferenças no desempenho dos coelhos quando o milho foi substituído pelo milheto Comum. Foram observados efeitos quadráticos dos níveis de substituição do milho por milheto Iapar IA 98301. Menor ganho de peso, pior conversão alimentar e menor peso de carcaça foram obtidos, respectivamente, com a substituição de 64,$09 ; 58,03$ e 63,58\% de milheto IA 98301 às rações, entretanto, com $100 \%$ de substituição os resultados foram satisfatórios. Pode-se concluir que os cultivares de milheto estudados apresentaram bom valor nutritivo e que, o milheto Comum ou Iapar IA 98301 podem substituir o milho nas rações de coelhos em crescimento.
\end{abstract}

Palavras-chave: alimentação, carcaça, digestibilidade, valor energético

\section{Nutritive Value and Performance of Growing Rabbits on Fed Rations Containing Pearl Millet (Pennisetum glaucum (L.) R.Br}

\begin{abstract}
Three experiments were carried out to determine the nutritive value and to evaluate the performance of growing rabbits on fed isoenergy rations containing different pearl millet levels. In a digestibility assay (experiment 1) the nutritive values of Common, BN2 and Iapar IA 98301 pearl millet were determined for 40 male New Zealand White rabbits, 45 days old, allotted in a completely randomized design, with 10 replications. Pearl millet replaced $30 \%$ of reference ration in each treatment. Values of digestible energy of Common, BN2 and Iapar IA 98301 pearl millet were respectively 3410; 3493 and $3505 \mathrm{kcal} / \mathrm{kg}$ (as feed basis). In performance assay (experiments 2 and 3) rations containing increased levels of Common or Iapar IA 98301 pearl millet cultivars (0, 25, 50, 75 and 100\%) substituted corn. In each experiment $60 \mathrm{New}$ Zealand White rabbits ( 30 males and 30 females), 40 days old, were alloted in a completely randomized design, with 12 replications each. No differences were observed $(\mathrm{P}>0.05)$ in growing rabbits performance when Common pearl millet replaced corn. Quadratic effect was reported when corn replaced Iapar IA 98301. Lower weight gain, worse feed:gain ratio and lower carcass weight were obtained, respectively, at 64.09; 58.03 and 63.58\% Iapar IA 98301 pearl millet level. However, results were satisfactory for $100 \%$ replacement. It may be concluded that pearl millet has good nutritive value and Common or Iapar IA 98301 pearl millet cultivars may replace corn in growing rabbits rations.
\end{abstract}

Key Words: digestibility, carcass, energy value, feeding

\section{Introdução}

A avaliação de alimentos energéticos alternativos em rações animais representa uma prática importante para disponibilizar fontes opcionais de ingredientes para substituir o milho, sem perdas no desempenho animal e que sejam economicamente interessantes. Dentre estes alimentos, o milheto (Pennisetum glaucum (L.) R. Br) vem sendo objeto de avaliação para uso em rações.

Além da resistência à falta de água e ao calor, o milheto apresenta bom desenvolvimento em solos

\footnotetext{
${ }_{1}$ Professores do Departamento de Zootecnia da Universidade Estadual de Maringá. Av. Colombo, 5790, CEP: $87020-900$. E.mail: acfurlan@uem.br

2 Alunos do curso de Zootecnia da UEM. Bolsistas de Iniciação Científica - PIBIC/CNPq-UEM

3 Zootecnista do Biotério Central da UEM.
} 
ácidos e com baixo teor de matéria orgânica (Andrews \& Kumar, 1992), sendo promissor para muitos solos brasileiros.

O teor de proteína bruta $(\mathrm{PB})$ do milheto é superior ao do milho, assim, ocorre redução da inclusão de aminoácidos nas rações. De acordo com Ejeta et al. (1987), o grão de milheto apresenta teor de aminoácidos semelhante ao trigo, à cevada e ao arroz.

Dados do NRC (1998) mostram teores de PB de $11,1 \%$ para o milheto e de $8,3 \%$ para o milho. Rostagno et al. (2000) avaliaram a composição química do milheto e do milho, obtida em experimentos realizados no Brasil e verificaram valores superiores de $\mathrm{PB}(12,08$ vs $8,57 \%)$, de gordura ( 4,19 vs $3,46 \%$ ) e de energia bruta ( 3980 vs $3933 \mathrm{kcal} / \mathrm{kg}$ ) em relação ao milho. Estes valores encontram-se próximos aos obtidos por Adeola \& Orban (1995) e Lawrence et al. (1995).

Valores inferiores de energia digestível e metabolizável, em relação ao milho, são mostrados para suínos e aves (NRC, 1998; Albino et al., 1992; Rodrigues et al., 1999), e podem estar relacionados com o maior teor de fibra bruta presente no milheto (Lawrence et al., 1995).

De acordo com Rostagno et al. (2000), o milheto apresenta $3,79 \%$ de FB, $11,30 \%$ de FDA e $19,33 \%$ de FDN, e o milho 1,95; 3,42 e 11,40\%, respectivamente. Os teores de minerais do milheto e do milho são semelhantes, principalmente cálcio e fósforo disponível, $0,03 \%$ e $0,08 \%$, respectivamente.

Entretanto, verifica-se que em função do grande número de cultivares de milheto existentes, ocorre variação acentuada nos teores de nutrientes, principalmente de PB (Singh et al., 1987) e, conseqüentemente, do valor energético.

A utilização do milheto nas rações de monogástricos, principalmente, aves, suínos e peixes tem sido avaliada. Para coelhos não foram encontrados na literatura brasileira trabalhos sobre a utilização do milheto em rações.

Abade \& Gomez (1984) obtiveram, com a utilização de altos níveis de milheto, ganhos de peso superiores aos obtidos com a utilização de milho em rações de frangos de corte em crescimento e terminação. Por outro lado, Café et al. (1994) e Stringhini (1994) não observaram, respectivamente, diferenças na postura e na qualidade do ovo de poedeiras comerciais e codornas japonesas em postura recebendo rações isoenergéticas contendo milheto em substituição ao milho.

O nível de $40 \%$ de substituição do milho pelo milheto em tambaquis (Colossoma macropomum) proporcionou maior ganho de peso diário quando comparado aos níveis de 20 e $60 \%$ de substituição (Silva et al., 1996).

Trabalhos desenvolvidos por Bastos (1999) com suínos demonstraram que a adição de milheto às rações de suínos foi viável até o nível de 36\%, dependendo apenas de sua disponibilidade e do preço de mercado.

Pelo exposto, o presente trabalho teve como objetivo determinar o valor nutritivo de três cultivares de milheto (Comum, BN2 e Iapar IA 98301) e avaliar o desempenho de coelhos em crescimento alimentados com rações contendo níveis crescentes do milheto Comum ou Iapar IA 98301.

\section{Material e Métodos}

Três experimentos foram conduzidos no setor de Cunicultura da Fazenda Experimental de Iguatemi da Universidade Estadual de Maringá.

Em um ensaio de metabolismo (Experimento 1), foram avaliados três cultivares de milheto (Comum, BN2 e Iapar IA 98301) utilizando 40 coelhos machos da raça Nova Zelândia Branco, com idade média de 45 dias, alojados em gaiolas individuais de metabolismo, de arame galvanizado, com bebedouro automático e comedouro semi-automático de chapa galvanizada, instaladas em galpão de alvenaria, pé direito de três metros, com cobertura de telha de barro.

Em cada tratamento, os milhetos avaliados substituíram 30\%, com base da matéria natural, de uma ração referência (Tabela 1), formulada para coelhos em crescimento com base nas exigências nutricionais do AEC (1987). O fornecimento de água e ração foi à vontade.

O período experimental teve duração de onze dias, dos quais sete foram para adaptação dos animais às instalações e rações e quatro dias para a coleta de fezes.

As análises das rações e das excretas foram realizadas de acordo com as metodologias descritas por Silva (1990). Para os cálculos de energia digestível (ED), proteína digestível (PD), FDA digestível (FDAD) e FDN digestível (FDND), dos cultivares de milheto avaliados, foi utilizada a metodologia descrita por Matterson et al. (1965).

Os animais foram distribuídos em um delineamento inteiramente casualizado, com quatro tratamentos e 10 repetições, sendo a unidade experimental constituída por um animal. Os resultados foram analisados pelo programa SAEG versão 7.1 (UFV, 1997). 
Tabela 1 - Composição percentual e química da ração referência, base matéria natural (Experimento 1)

Table 1 - Chemical and percentual composition of the reference ration, as fed basis (Experiment 1)

\begin{tabular}{|c|c|}
\hline $\begin{array}{l}\text { Ingredientes } \\
\text { Ingredients }\end{array}$ & $\begin{array}{l}\text { Ração referência } \\
\text { Reference ration }\end{array}$ \\
\hline Milho & 27,60 \\
\hline \multicolumn{2}{|l|}{ Corn } \\
\hline Feno de alfafa & 30,00 \\
\hline \multicolumn{2}{|l|}{ Alfalfahay } \\
\hline Feno de aveia & 11,10 \\
\hline \multicolumn{2}{|l|}{ Oat hay } \\
\hline Farelo de trigo & 19,00 \\
\hline \multicolumn{2}{|l|}{ Wheat meal } \\
\hline Farelo de soja & 8,19 \\
\hline \multicolumn{2}{|l|}{ Soybean meal } \\
\hline Sal & 0,40 \\
\hline \multicolumn{2}{|l|}{ Salt } \\
\hline Fosfato bicálcico & 0,67 \\
\hline \multicolumn{2}{|l|}{ Dicalcium phosphate } \\
\hline Calcário & 0,28 \\
\hline \multicolumn{2}{|l|}{ Limestone } \\
\hline DL-Metionina & 0,12 \\
\hline \multicolumn{2}{|l|}{ DL-Methionine } \\
\hline L-Lisina HCL & 0,14 \\
\hline \multicolumn{2}{|l|}{$L$-Lysine $H C L$} \\
\hline Mist. Vit+Min ${ }^{1}$ & 0,50 \\
\hline \multicolumn{2}{|l|}{ Vit. and min. supplement } \\
\hline Oleo vegetal & 2,00 \\
\hline \multicolumn{2}{|l|}{ Vegetable oil } \\
\hline Valores calculados & 100,00 \\
\hline \multicolumn{2}{|l|}{ Calculated values } \\
\hline Proteína bruta (\%) & 16,00 \\
\hline \multicolumn{2}{|l|}{ Crude protein } \\
\hline Energia digestível (kcal/kg) & 2550 \\
\hline \multicolumn{2}{|l|}{ Digestible energy } \\
\hline Fibra bruta (\%) & 13,00 \\
\hline \multicolumn{2}{|l|}{ Crude fiber } \\
\hline P total $(\%)$ & 0,50 \\
\hline \multicolumn{2}{|l|}{ Total P } \\
\hline $\mathrm{Ca}(\%)$ & 0,80 \\
\hline Lisina $(\%)$ & 0,80 \\
\hline \multicolumn{2}{|l|}{ Lysine } \\
\hline Met.+Cis. $(\%)$ & 0,60 \\
\hline \multicolumn{2}{|c|}{ 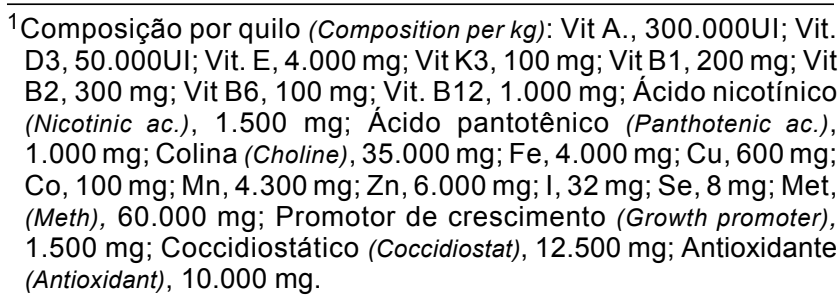 } \\
\hline
\end{tabular}

Dois experimentos de desempenho foram conduzidos para avaliar os cultivares de milheto Comum (Experimento 2) e Iapar IA 98301 (Experimento 3). Em cada experimento, foram utilizados 60 coelhos da Raça Nova Zelândia Branco, 30 machos e 30 fêmeas, com 40 dias de idade, alojados, individualmente, em gaiolas de arame galvanizado, providas de bebedouro automático e comedouro semi-automático de chapa galvanizada, localizados em galpão de alvenaria, com cobertura de telha francesa, pé direito de três metros, piso de alvenaria, paredes laterais de 0,5 metros em alvenaria e o restante em tela e cortina de plástico para controle de ventos. A temperatura média registrada no período experimental foi de $25^{\circ} \mathrm{C}$, sendo que a máxima registrada foi de $35^{\circ} \mathrm{C}$ e a mínima, $15^{\circ} \mathrm{C}$. O fornecimento das rações e da água foi à vontade.

As rações utilizadas nos experimentos (Tabelas 2 e 3 ) foram formuladas para atender o mínimo recomendado pelo AEC (1987) para coelhos em crescimento, sendo isoprotéicas, isocalóricas, isoaminoacídicas para metionina+cistina e lisina, isofibrosas, isocálcicas e isofosfóricas. Em cada experimento, os tratamentos consistiram de uma ração testemunha e outras quatro rações, onde o milheto (Comum ou Iapar IA 98301) substituiu o milho comum em 25, 50, 75 e $100 \%$.

Para o cálculo das rações, os teores de energia digestível(ED) dos milhetos Comum e Iapar IA 98301 utilizados foram de 3410 e $3505 \mathrm{kcal}$ de $\mathrm{ED} / \mathrm{kg} \mathrm{MN}$, respectivamente, determinados no Experimento 1.

Os coelhos foram pesados no início do experimento, com 40 dias de idade e no final, com 80 dias, quando foram abatidos pela técnica do atordoamento seguida por sangria e retirada das patas, pele, cauda, cabeça e vísceras e pesagem da carcaça.

Os animais foram distribuídos em delineamento experimental inteiramente casualizado, com cinco tratamentos e 12 repetições, sendo a unidade experimental constituída por um animal. Os resultados foram analisados pelo programa SAEG versão 7.1 (UFV, 1997). 
Tabela 2 - Composição percentual e química das rações experimentais contendo milheto comum em substituição ao milho, base matéria natural (Experimento 2)

Table 2 - Chemical and percentual composition of the experimental rations containing common pearl millet in replacement to corn, as fed basis (Experiment 2)

\begin{tabular}{|c|c|c|c|c|c|}
\hline \multirow[t]{2}{*}{$\begin{array}{l}\text { Ingredientes } \\
\text { Ingredients }\end{array}$} & \multicolumn{5}{|c|}{$\begin{array}{l}\text { \% de substituição } \\
\text { \% of replacement }\end{array}$} \\
\hline & 0,00 & 25,00 & 50,00 & 75,00 & 100,00 \\
\hline Milho & 25,00 & 18,75 & 12,47 & 6,23 & 0,00 \\
\hline Corn & & & & & \\
\hline Milheto comum & 0,00 & 6,13 & 12,26 & 18,39 & 24,51 \\
\hline $\begin{array}{l}\text { Common pearl millet } \\
\text { Farelo de soja }\end{array}$ & 10,00 & 10,00 & 10,00 & 10,00 & 10,00 \\
\hline $\begin{array}{l}\text { Soybean meal } \\
\text { Farelo de trigo } \\
\text { Wheat meal }\end{array}$ & 20,00 & 20,00 & 20,00 & 20,00 & 20,00 \\
\hline $\begin{array}{l}\text { Feno de alfafa } \\
\text { Alfalfa hay }\end{array}$ & 26,00 & 26,00 & 26,00 & 26,00 & 26,00 \\
\hline $\begin{array}{l}\text { Feno de aveia } \\
\text { Oat hay }\end{array}$ & 14,25 & 14,40 & 14,58 & 14,72 & 14,85 \\
\hline $\begin{array}{l}\text { Sal } \\
\text { Salt }\end{array}$ & 0,50 & 0,50 & 0,50 & 0,50 & 0,50 \\
\hline $\begin{array}{l}\text { Fosfato bicálcico } \\
\text { Dicalcium phosphate } \\
\text { Calcário }\end{array}$ & 0,62 & 0,65 & 0,65 & 0,65 & 0,65 \\
\hline $\begin{array}{l}\text { Limestone } \\
\text { DL-Metionina }\end{array}$ & $\begin{array}{l}0,43 \\
0,10\end{array}$ & $\begin{array}{l}0,39 \\
0,10\end{array}$ & $\begin{array}{l}0,39 \\
0,09\end{array}$ & $\begin{array}{l}0,39 \\
0,08\end{array}$ & $\begin{array}{l}0,39 \\
0,08\end{array}$ \\
\hline DL-Methionine & & & & & \\
\hline $\begin{array}{l}\text { L-Lisina HCL } \\
\text { L-Lysine } H C L\end{array}$ & 0,09 & 0,08 & 0,07 & 0,06 & 0,05 \\
\hline $\begin{array}{l}\text { Antioxidante } \\
\text { Antioxindant }\end{array}$ & 0,01 & 0,01 & 0,01 & 0,01 & 0,01 \\
\hline $\begin{array}{l}\text { Mist. Vit }+\operatorname{Min}^{1} \\
\text { Vit. and min. suplement }{ }^{1}\end{array}$ & 0,50 & 0,50 & 0,50 & 0,50 & 0,50 \\
\hline $\begin{array}{l}\text { Óleo vegetal } \\
\text { Vegetable oil }\end{array}$ & 2,50 & 2,49 & 2,48 & 2,47 & 2,46 \\
\hline $\begin{array}{l}\text { Total } \\
\text { Valores calculados }\end{array}$ & 100,00 & 100,00 & 100,00 & 100,00 & 100,00 \\
\hline Calculated values & & & & & \\
\hline $\begin{array}{l}\text { Proteína bruta }(\%) \\
\text { Crude protein }\end{array}$ & 16,97 & 16,55 & 16,82 & 17,09 & 17,37 \\
\hline $\begin{array}{l}\text { Energia digestível }(\mathrm{kcal} / \mathrm{kg}) \\
\text { Digestible energy }\end{array}$ & 2560 & 2560 & 2560 & 2560 & 2560 \\
\hline $\begin{array}{l}\text { Fibra bruta }(\%) \\
\text { Crude fiber }\end{array}$ & 13,07 & 13,20 & 13,33 & 13,45 & 13,58 \\
\hline $\begin{array}{l}\text { P total }(\%) \\
\text { Total P }\end{array}$ & 0,50 & 0,50 & 0,50 & 0,50 & 0,50 \\
\hline $\mathrm{Ca}(\%)$ & 0,80 & 0,80 & 0,80 & 0,80 & 0,80 \\
\hline Lisina $(\%)$ & 0,80 & 0,80 & 0,80 & 0,80 & 0,80 \\
\hline $\begin{array}{l}\text { Lysine } \\
\text { Met.+Cis. (\%) } \\
\text { Met }+ \text { Cys }\end{array}$ & 0,60 & 0,60 & 0,60 & 0,60 & 0,60 \\
\hline
\end{tabular}

${ }^{1}$ Composição por quilo (Composition per kg): Vit A., 300.000UI; Vit. D3, 50.000UI; Vit. E, 4.000 mg; Vit K3, 100 mg; Vit B1, 200 mg; Vit B2, 300 mg; Vit B6, 100 mg; Vit. B12, 1.000 mg; Ácido nicotínico (Nicotinic ac.), 1.500 mg; Ácido pantotênico (Panthotenic ac.), $1.000 \mathrm{mg}$; Colina (Choline), 35.000 mg; Fe, 4.000 mg; Cu, 600 mg; Co, 100 mg; Mn, 4.300 mg; Zn, 6.000 mg; I, 32 mg; Se, 8 mg; Met (Meth), 60.000 mg; Promotor de crescimento (Growth promoter), $1.500 \mathrm{mg}$; Coccidiostático (Coccidiostat), $12.500 \mathrm{mg}$; Antioxidante (Antioxidant), $10.000 \mathrm{mg}$. 
Tabela 3 - Composição percentual e química das rações experimentais contendo milheto lapar IA 98301 em substituição ao milho, base matéria natural (Experimento 3)

Table 3 - Chemical and percentual composition of the experimental rations containing lapar IA 98301 pearl millet in replacement to corn, as fed basis (Experiment 3)

\begin{tabular}{|c|c|c|c|c|c|}
\hline \multirow[t]{2}{*}{$\begin{array}{l}\text { Ingredientes } \\
\text { Ingredients }\end{array}$} & \multicolumn{5}{|c|}{$\begin{array}{l}\text { \% de substituição } \\
\% \text { of replacement }\end{array}$} \\
\hline & 0,00 & 25,00 & 50,00 & 75,00 & 100,00 \\
\hline Milho & 25,00 & 18,75 & 12,50 & 6,25 & 0,00 \\
\hline Corn & & & & & \\
\hline $\begin{array}{l}\text { Milheto Iapar IA } 98301 \\
\text { Iapar IA } 98301 \text { pearl millet }\end{array}$ & 0,00 & 5,97 & 11,93 & 17,89 & 23,86 \\
\hline Farelo de soja & 10,00 & 10,00 & 10,00 & 10,00 & 10,00 \\
\hline $\begin{array}{l}\text { Soybean meal } \\
\text { Farelo de trigo } \\
\text { Wheat meal }\end{array}$ & 20,00 & 20,00 & 20,00 & 20,00 & 20,00 \\
\hline $\begin{array}{l}\text { Feno de alfafa } \\
\text { Alfalfa hay }\end{array}$ & 26,00 & 26,00 & 26,00 & 26,00 & 25,68 \\
\hline $\begin{array}{l}\text { Feno de aveia } \\
\text { Oat hay }\end{array}$ & 14,25 & 14,60 & 14,97 & 15,34 & 16,00 \\
\hline $\begin{array}{l}\text { Sal } \\
\text { Salt }\end{array}$ & 0,50 & 0,50 & 0,50 & 0,50 & 0,50 \\
\hline $\begin{array}{l}\text { Fosfato bicálcico } \\
\text { Dicalcium phosphate } \\
\text { Calcário }\end{array}$ & 0,62 & 0,63 & 0,63 & 0,64 & 0,65 \\
\hline $\begin{array}{l}\text { Limestone } \\
\text { DL-Metionina }\end{array}$ & 0,43 & 0,41 & 0,40 & 0,38 & 0,38 \\
\hline $\begin{array}{l}\text { DL-Methionine } \\
\text { L-Lisina HCL }\end{array}$ & 0,10 & 0,10 & 0,09 & 0,08 & 0,07 \\
\hline $\begin{array}{l}\text { L-Lysine } H C L \\
\text { Antioxidante }\end{array}$ & 0,09 & 0,08 & 0,07 & 0,06 & 0,05 \\
\hline $\begin{array}{l}\text { Antioxidant } \\
\text { Mist. Vit }+ \text { Min }^{1}\end{array}$ & 0,01 & 0,01 & 0,01 & 0,01 & 0,01 \\
\hline $\begin{array}{l}\text { Vit. and min. supplement } \\
\text { Óleo vegetal }\end{array}$ & 0,50 & 0,50 & 0,50 & 0,50 & 0,50 \\
\hline Vegetable oil & 2,50 & 2,45 & 2,40 & 2,35 & 2,30 \\
\hline $\begin{array}{l}\text { Total } \\
\text { Valores calculados }\end{array}$ & 100,00 & 100,00 & 100,00 & 100,00 & 100,00 \\
\hline $\begin{array}{l}\text { Calculated values } \\
\text { Proteína bruta }(\%) \\
\text { Crude protein }\end{array}$ & 16,97 & 16,42 & 16,71 & 16,92 & 17,12 \\
\hline $\begin{array}{l}\text { Energia digestível }(\mathrm{kcal} / \mathrm{kg}) \\
\text { Digestible energy }\end{array}$ & 2560 & 2560 & 2560 & 2560 & 2560 \\
\hline $\begin{array}{l}\text { Fibra bruta (\%) } \\
\text { Crude fiber }\end{array}$ & 13,07 & 13,03 & 13,04 & 13,03 & 13,03 \\
\hline $\begin{array}{l}\text { P total }(\%) \\
\text { Total P }\end{array}$ & 0,50 & 0,50 & 0,50 & 0,50 & 0,50 \\
\hline $\begin{array}{l}\mathrm{Ca}(\%) \\
\text { Lisina }(\%)\end{array}$ & $\begin{array}{l}0,80 \\
0,80\end{array}$ & $\begin{array}{l}0,80 \\
0,80\end{array}$ & $\begin{array}{l}0,80 \\
0,80\end{array}$ & $\begin{array}{l}0,80 \\
0,80\end{array}$ & $\begin{array}{l}0,80 \\
0,80\end{array}$ \\
\hline Lysine & & & & & \\
\hline $\begin{array}{l}\text { Met.+Cis. }(\%) \\
\text { Met }+ \text { Cys }\end{array}$ & 0,60 & 0,60 & 0,60 & 0,60 & 0,60 \\
\hline
\end{tabular}

${ }^{1}$ Composição por quilo (Composition per kg): Vit A., 300.000UI; Vit. D3, 50.000Ul; Vit. E, 4.000 mg; Vit K3, 100 mg; Vit B1, 200 mg; Vit B2, $300 \mathrm{mg}$; Vit B6, $100 \mathrm{mg}$; Vit. B12, $1.000 \mathrm{mg}$; Ácido nicotínico (Nicotinic ac.), $1.500 \mathrm{mg}$; Ácido pantotênico (Panthotenic ac.), $1.000 \mathrm{mg}$; Colina (Choline), 35.000 mg; Fe, 4.000 mg; Cu, 600 mg; Co, 100 mg; Mn, 4.300 mg; Zn, 6.000 mg; I, 32 mg; Se, 8 mg; Met (Meth), 60.000 mg; Promotor de crescimento (Growth promoter), $1.500 \mathrm{mg}$; Coccidiostático (Coccidiostat), $12.500 \mathrm{mg}$; Antioxidante (Antioxidant), $10.000 \mathrm{mg}$. 


\section{Resultados e Discussão}

Avaliando a composição química dos cultivares de milheto estudados (Tabela 4), verificaram-se maiores teores de PB e EE para o milheto do cultivar comum. Estes teores são bastantes variados, de acordo com o cultivar, solo, entre outros fatores. Singh et al. (1987), trabalhando com diferentes cultivares, encontraram valores protéicos variando entre 9,9 e $20,8 \%$ e teores de EE entre 4,1 e $5,4 \%$. Os teores de $\mathrm{PB}$ dos cultivares BN2 e Iapar foram numericamente inferiores e semelhantes.

Os coeficientes de digestibilidade aparente da matéria seca (CDMS) e da energia bruta (CDEB) das rações testes, foram maiores $(\mathrm{P}<0,05)$ que os da ração referência, indicando superioridade dos milhetos avaliados. Não foram observadas diferenças $(\mathrm{P}>0,05)$ entre os coeficientes de digestibilidade aparente da proteína bruta (CDPB) e da fibra em detergente neutro (CDFDN) das rações avaliadas.
Não houve diferença $(\mathrm{P}>0,05)$ para os $\mathrm{CD}$ da proteína bruta dos milhetos estudados (Tabela 5), entretanto, os CD da fibra em detergente neutro (FDN) dos milhetos Comum (22,17\%) e BN2 $(23,41 \%)$ foram inferiores $(\mathrm{P}<0,05)$ aos do milheto Iapar IA $98301(29,99 \%)$.

Os teores de energia digestível aparente para os milhetos comum, BN2 e Iapar IA 98301 foram, respectivamente de 3410,3493 e $3505 \mathrm{kcal} / \mathrm{kg}$ de matéria natural (Tabela 6).

Estes valores são considerados muito bons e estão próximos aos obtidos em pesquisas, ainda não publicadas pelos autores, para o sorgo $(3302 \mathrm{kcal} / \mathrm{kg})$, triticale (3.372 kcal $/ \mathrm{kg}$ ) e triguilho (3420 kcal $/ \mathrm{kg}$ ) e por Scapinello (1993) para o milho comum (3345 kcal $/ \mathrm{kg})$.

Não foram observadas diferenças $(P>0,05)$ no desempenho de coelhos à medida que o milho foi substituído pelo milheto Comum (Experimentos 2 e 3 ), evidenciando a boa perspectiva de uso deste alimento nas rações (Tabela 7).

Tabela 4 - Composição percentual e química dos cultivares de milheto Comum, BN2 e lapar IA 98301* Table 4 - Chemical and percentual composition of the Common, BN2 and lapar IA 98301 pearl millet cultivars

\begin{tabular}{lcccccccc}
\hline & $\begin{array}{c}\mathrm{MS}(\%)^{1} \\
D M^{1}\end{array}$ & $\begin{array}{c}\mathrm{EB}(\mathrm{kcal} / \mathrm{kg})^{2} \\
G E^{2}\end{array}$ & $\mathrm{EE}(\%)^{3}$ & $\begin{array}{c}\mathrm{PB}(\%)^{4} \\
C P^{4}\end{array}$ & $\begin{array}{c}\mathrm{FDA}(\%)^{5} \\
A^{5} F^{5}\end{array}$ & $\begin{array}{c}\mathrm{FDN}(\%)^{6} \\
\text { NDF }\end{array}$ & $\begin{array}{c}\text { Calcio(\%) } \\
\text { Calcium }\end{array}$ & $\begin{array}{c}\text { Fósforo (\%) } \\
\text { Phosphorus }\end{array}$ \\
\hline Comum & 89,34 & 4099 & 4,67 & 13,76 & 3,39 & 11,65 & 0,032 & 0,27 \\
Common & & & & & & & & \\
BN2 & 88,28 & 3988 & 3,80 & 11,45 & 3,08 & 16,05 & 0,030 & 0,305 \\
Iapar IA 98301 & 88,91 & 4006 & 3,29 & 11,57 & 3,48 & 10,88 & 0,033 & 0,311 \\
\hline
\end{tabular}

* Valores obtidos no Laboratório de Alimentos e Nutrição Animal do Departamento de Zootecnia da UEM (Base na Matéria Natural.)

* Obtained values from Food and Animal Nutrition Laboratory of Animal Science Department of UEM (as fed basis)

${ }^{1}$ Matéria seca, ${ }^{2}$ Energia bruta, ${ }^{3}$ Extrato etéreo, ${ }^{4}$ Proteína bruta, ${ }^{5}$ Fibra em detergente ácido, ${ }^{6}$ Fibra em detergente neutro.

${ }^{1}$ Dry matter, ${ }^{2}$ Gross energy, ${ }^{3}$ Ether extract, ${ }^{4}$ Crude protein, ${ }^{5}$ Acid detergent fiber, ${ }^{6}$ Neutral detergent fiber.

Tabela 5 - Coeficientes de digestibilidade aparente da matéria seca (CDMS), energia bruta (CDEB), proteína bruta (CDPB) e fibra em detergente neutro (CDFDN) dos milhetos dos cultivares Comum, BN2 e lapar IA 98301

Table 5 - Apparent digestibility coefficient of dry matter (DCDM), crude energy (DCGE), crude protein (DCCP), and neutral detergent fiber (DCNDF) of Common, BN2 and lapar IA98301 pearl millet cultivars

\begin{tabular}{lcccc}
\hline $\begin{array}{l}\text { Milheto } \\
\text { Pearl millet }\end{array}$ & $\begin{array}{c}\text { CDMS (\%) } \\
\text { DCDM }^{*}\end{array}$ & $\begin{array}{c}\text { CDEB }(\%)^{*} \\
D C G E^{*}\end{array}$ & $\begin{array}{c}\text { CDPB (\%) } \\
\text { DCCP }\end{array}$ & $\begin{array}{c}\text { CDFDN (\%) } \\
\text { DCNDF }\end{array}$ \\
\hline Comum & $85,62^{\mathrm{b}}$ & $83,16^{\mathrm{b}}$ & 75,86 & $22,17^{\mathrm{b}}$ \\
Common & $88,26^{\mathrm{a}}$ & $87,61^{\mathrm{a}}$ & 87,65 & $23,41^{\mathrm{b}}$ \\
BN2 & $88,14^{\mathrm{a}}$ & $87,49^{\mathrm{a}}$ & 83,51 & $29,99^{\mathrm{a}}$ \\
Iapar IA 98301 & 3,75 & 4,83 & 10,63 & 17,11 \\
Coeficiente de variação (\%) & & & \\
Coefficient of variation & & &
\end{tabular}

* Médias seguidas de letras diferentes, na coluna, diferem $(P<0,05)$ pelo teste Tukey.

* Means, in a column, followed by different letters, differ $(P<0.05)$ by Tukey test . 
Tabela 6 - Valores de energia digestível (ED), proteína digestível (PD) e fibra em detergente neutro digestível (FDND) dos milhetos dos cultivares Comum, BN2 e lapar IA 98301

Table 6 - Values of digestible energy (DE), digestible protein (DP) and digestible neutral detergent fiber (DNDF) of the Common, BN2 and lapar IA98301 pearl millet cultivars

\begin{tabular}{|c|c|c|c|}
\hline Milhetos & $\mathrm{D}^{*}(\mathrm{kcal} / \mathrm{l}$ & $\mathrm{PD}(\%)$ & $\operatorname{FDND}(\%)$ \\
\hline Pearlmillet & $D E^{*}$ & $D P D$ & $N D F$ \\
\hline Comum & $3410^{b}$ & 10,44 & $2,58^{\mathrm{b}}$ \\
\hline Common & & & \\
\hline BN2 & $3493^{\mathrm{a}}$ & 10,04 & $3,76^{\mathrm{a}}$ \\
\hline Iapar IA 98301 & $3505^{\mathrm{a}}$ & 9,66 & $3,26^{\mathrm{ab}}$ \\
\hline Coeficiente de variação (\%) & 0) 4,82 & 10,56 & 17,01 \\
\hline
\end{tabular}

Coefficient of variation

${ }^{*}$ Médias seguidas de letras diferentes, na coluna, diferem pelo teste Tukey $(\mathrm{P}<0,05)$.

* Means, in a column, followed by different letters, differ by Tukey test $(P<0.05)$.
Foram verificados efeitos quadráticos $(\mathrm{P}<0,05)$ dos níveis de substituição do milho pelo milheto Iapar IA 98301, e os valores estimados para menor ganho de peso, pior conversão alimentar e menor peso de carcaça em 64,09; 58,03 e 63,58\% de inclusão deste milheto às rações, respectivamente. Entretanto, com $100 \%$ de substituição, os resultados de desempenho foram satisfatórios, mostrando ser possível a substituição total do milho pelo milheto Iapar IA 98301.

Não foi observado efeito $(\mathrm{P}>0,05)$ do sexo sobre o desempenho dos animais nos dois experimentos realizados.

Os bons resultados de desempenho proporcionados com as rações com altos níveis de inclusão do milheto evidenciam o bom valor nutritivo deste alimento. A inclusão de milheto na alimentação de

Tabela 7 - Ganho de peso diário (GPD), consumo de ração diário (CRD), conversão alimentar (CA), peso da carcaça (PCAR) e rendimento de carcaça (RCAR) de coelhos em crescimento alimentados com rações contendo diferentes níveis de milheto dos cultivares Comum ou lapar IA 98301 em substituição ao milho

Table 7 - Daily weight gain (WGD), daily feed intake (FID), feed:gain ratio (FGR), carcass weigh (CARW) and carcass yield (CARY) of rabbits fed rations containing different levels of common or lapar IA 98301 pearl millet cultivars in replacement to corn

\begin{tabular}{|c|c|c|c|c|c|c|}
\hline & \multicolumn{5}{|c|}{$\begin{array}{l}\% \text { de substituição } \\
\% \text { of replacement }\end{array}$} & \multirow[t]{2}{*}{$\mathrm{CV}(\%)$} \\
\hline & 0,00 & 25,00 & 50,00 & 75,00 & 100,00 & \\
\hline & \multicolumn{5}{|c|}{$\begin{array}{l}\text { Milheto comum (Experimento } 2 \text { ) } \\
\text { Common pearl millet (Experiment 2) }\end{array}$} & \\
\hline $\begin{array}{l}\mathrm{GPD}(\mathrm{g}) \\
W G D \\
\mathrm{CRD}(\mathrm{g})\end{array}$ & 25,65 & 27,41 & 27,03 & 23,29 & 26,87 & 16,11 \\
\hline $\begin{array}{l}\text { FID } \\
\mathrm{CA}\end{array}$ & 90,80 & 98,95 & 93,79 & 87,57 & 96,46 & 12,01 \\
\hline $\begin{array}{l}F G R \\
\operatorname{PCAR}(\mathrm{g})\end{array}$ & 3,54 & 3,61 & 3,47 & 3,76 & 3,59 & 7,91 \\
\hline $\begin{array}{l}C A R W \\
\operatorname{RCAR}(\%)\end{array}$ & 1029 & 1081 & 1065 & 972 & 1069 & 9,44 \\
\hline \multirow[t]{2}{*}{$C A R Y$} & 47,36 & 48,41 & 47,94 & 46,57 & 48,30 & 4,13 \\
\hline & \multicolumn{5}{|c|}{$\begin{array}{l}\text { Milheto Iapar IA } 98301 \text { (Experimento 3) } \\
\text { Iapar IA } 98301 \text { pearl millet (Experiment 3) }\end{array}$} & \\
\hline $\begin{array}{l}\operatorname{GPMD}(\mathrm{g})^{1} \\
M W G D^{I}\end{array}$ & 28,52 & 28,68 & 25,12 & 26,31 & 27,84 & 9,10 \\
\hline $\begin{array}{l}\text { CRMD }(\mathrm{g}) \\
\text { MFID }\end{array}$ & 105,60 & 108,12 & 99,73 & 101,21 & 104,30 & 5,93 \\
\hline $\begin{array}{l}\mathrm{CA}^{2} \\
F G R^{1}\end{array}$ & 3,71 & 3,78 & 3,98 & 3,86 & 3,75 & 6,67 \\
\hline $\begin{array}{l}\operatorname{PCAR}(\mathrm{g})^{3} \\
C A R W^{I}\end{array}$ & 1118 & 1116 & 1025 & 1059 & 1087 & 6,30 \\
\hline $\begin{array}{l}\operatorname{RCAR}(\%) \\
C A R Y\end{array}$ & 49,11 & 49,04 & 48,15 & 48,57 & 48,46 & 3,31 \\
\hline
\end{tabular}

${ }^{1}$ Efeito quadrático $(P<0,05)$ dos níveis de substituição $\left(Y=33,72-0,25956 x+0,002025 x^{2} ; r^{2}=0,83\right)$.

1 Quadratic effect $(P<.05)$ of replacement levels.

${ }^{2}$ Efeito quadrático $(P<0,05)$ dos níveis de substituição $\left(Y=3,52+0,01452 x+0,000125 x^{2} ; r^{2}=0,94\right)$

2 Quadratic effect $(P<.05)$ of replacement levels.

3 Efeito quadrático $(P<0,05)$ dos níveis de substituição $\left(Y=1222,07-5,8872 x+0,0463 x^{2} ; r^{2}=0,54\right)$.

${ }^{3}$ Quadratic effect $(P<.05)$ of replacement levels.

R. Bras. Zootec., v.32, n.1, p.123-131, 2003 
codornas para corte (Shrivastav et al., 1990) e marrecos de Pequim (Adeola et al, 1994 e Ragland et al., 1997) também apresentou resultados satisfatórios sobre o desempenho destes animais. Café et al. (1994) e Stringhini et al. (1994), trabalhando com poedeiras comerciais e codornas japonesas em postura, respectivamente, não observaram diferenças significativas quanto à produção $\mathrm{e}$ à qualidade dos ovos.

Melhores resultados de desempenho de frangos de corte foram obtidos por Abade \& Gomez (1984) com altos níveis de milheto na ração. Já Bastos (1999), com suínos em crescimento e terminação, mostrou a possibilidade de substituir $36 \%$ do milho pelo milheto.

Outro aspecto a ser evidenciado é a boa relação entre ácidos graxos ômega- 6 e ômega-3 existente no milheto, o que leva a uma menor relação entre estes ácidos na ração(Collins et al., 1997) e assim, consistindo em um aspecto favorável à saúde, tanto humana quanto animal, devido ao aumento na proporção de lipoproteínas de alta densidade (HDL) circulante no sangue.

Portanto, considerando o bom o valor energético obtido para os cultivares de milhetos estudados, os resultados de desempenho torna o milheto uma opção de grande valor para o uso nas rações de coelhos.

\section{Conclusões}

Os teores de energia digestível aparente para os milhetos comum, BN2 e Iapar IA 98301 foram, respectivamente, de 3410,3493 e $3505 \mathrm{kcal} / \mathrm{kg}$ de matéria natural.

A utilização do milheto em rações para coelhos em crescimento proporcionou resultados satisfatórios, não afetando o desempenho dos animais, podendo substituir o milho nas rações de coelhos em crescimento, ficando o seu uso na dependência da oferta e preço de mercado.

\section{Literatura Citada}

ABADE, A.N.; GOMEZ, M. Substituition of finger millet (Eleusine coracana) and bulrush millet (Pennisetum typhoides) for maize in broiler feeds. Animal Feed Science and Technology, v.10, p.291-299, 1984.

ADEOLA, O.; ORBAN, J.I. Chemical composition and nutrient digestibility of pearl millet (Pennisetum glaucum) fed to growing pigs. Journal of Cereal Science, v.22, p.177-184, 1995.

ADEOLA, O.; ROGLER, J.C.; SULLICAN, T.W. Pearl millet in diets of White Pekin ducks. Poultry Science, v.73, n.3, p.425-435, 1994.
AEC. Recomendações para nutrição animal. 5.ed. RhônePoulenc, 1987. 86p.

ALBINO, L.F.T.; FIALHO, E.T.; BRUM, P.A.R. et al. Determinação dos valores energéticos de alguns alimentos para aves. In: REUNIÃO ANUAL DA SOCIEDADE BRASILEIRA DE ZOOTECNIA, 29., 1992, Lavras. Anais... Lavras: Sociedade Brasileira de Zootecnia, 1992. p.330.

ANDREWS, D.J.; KUMAR, K.A. Pearl millet for food, feed and forage. Advances in Agronomy, v.48, p.89-139, 1992.

BASTOS, A.O. Utilização de diferentes níveis de grão de milheto (Pennisetum americanum L. Leeke) na alimentação de suínos. Ilha Solteira: Universidade Estadual Paulista "Júlio de Mesquita Filho", 1999. 43p. Dissertação (Mestrado em Zootecnia) - Universidade Estadual Paulista "Júlio de Mesquita Filho", 1999.

CAFÉ, M.B.; MOGYCA, N.S.M.; STRINGHINI, J.H. et al. Utilização do milheto como substituto do milho em rações para poedeiras comerciais. 1. Desempenho produtivo. In: CONGRESSO BRASILEIRO DE MEDICINA VETERINÁRIA, 23., 1994, Recife. Anais... Recife: SPEMVE, 1994. p.628.

COELLO, C.L. Consideraciones sobre la pigmentación de la yema del huevo y de los tarsos y piel de los pollos de engorda. In: CONFERENCIA APINCO DE CIÊNCIA E TECNOLOGIA AVÍCOLAS, 1993, Santos. Anais... Campinas: FACTA, 1993, p.95-110.

COLlins, V.P.; CANTOR, A.H.; PESCATORE, A.J. et al. Pearl millet in layer diets enhances egg yolk n-3 fatty acids. Poultry Science, v.76. p.326-330, 1997.

EJETA, G.; HASSEN, M.M.; MERTZ, E.T. In vitro digestibility of pearl millet (Pennisetum tiphoydes) and other cereals. Proceedings of National Academy of Sciences, v. 84, n.17, p.6016-6019, 1987.

LAWRENCE, B.V.; ADEOLA, O.; ROGLER, J.C. Nutrient digestibility and growth performance of pigs fed pearl millet as a replacement for corn. Journal of Animal Science, v. 73 . n.7, p.2026-2032, 1995.

MATTERSON, L.D.; POTTER, L.M.; STUTZ, N.W. et al. The metabolizable energy of feed ingredients of chickens. Research Reproduction, v.7, n.1, p.3-11, 1965.

MONTEIRO, R.T. Avaliação nutricional do milho e do triticale extrusados ou não na alimentação de coelhos em crescimento. Maringá: Universidade Estadual de Maringá, 2002. 55p. Dissertação (Mestrado em Zootecnia) - Universidade Estadual de Maringá, 2002.

NATIONAL RESEARCH COUNCIL - NRC. Nutrient requirements of swine. 20.ed. Washington D.C.: National Academy Press, 1998. 189p.

RAGLAND, D.; KING, D.; ADEOLA, O. Determination of metabolizable energy contents of feed ingredients for ducks. Poultry Science, v.76, n.9, p.1287-1291, 1997.

RODRIGUES, M.P.; GOMES, P.C.; ALBINO, L.F.T. et al. Determinação do valor energético do milheto e sua utilização em rações de frangos de corte de 1 a 21 dias de idade. In: REUNIÃO ANUAL DA SOCIEDADE BRASILEIRA DE ZOOTECNIA, 36., 1999, Porto Alegre. Anais... Porto Alegre: Sociedade Brasileira de Zootecnia, 1999. p.181.

ROSTAGNO, H.S.; ALBINO, L.F.T., DONZELE, J.L. et al. Tabelas brasileiras para aves e suínos (Composição de alimentos e exigências nutricionais). Viçosa, MG: Universidade Federal de Viçosa, 2000. 141p.

SCAPINELLO, C. Níveis de proteína bruta e de energia digestível e exigências de lisina e de metionina + cistina, 
para coelhos Nova Zelândia Branco, em crescimento. Viçosa, MG: Universidade Federal de Viçosa, 1993. 214p. Tese (Doutorado em Zootecnia) - Universidade Federal de Viçosa, 1993.

SHRIVASTAV, A.V.; PANDA, B.; DARSHAN, N. Comparative nutritive values of different cereals in quail diets. Indian Journal of Animal Science, v.60, n.6, p.720-724, 1990.

SILVA, D.J. Análise de alimentos (Métodos químicos e biológicos). Viçosa, MG: Universidade Federal de Viçosa, 1990. 165p.

SILVA, P.C.; FRANÇA, A.F.S.; JACOB, G. et al. Milheto Pennisetum americanum, como substituto do milho, na alimentação do tambaqui Colossoma macropomum. In: SIMPÓSIO BRASILEIRO DE AQUICULTURA, 9., 1996, Sete Lagoas. Anais... Sete Lagoas, 1996. p.232.
SINGH, P.; SINGH, U.; EGGUM, B.O. et al. Nutritional evaluation of high protein genotypes of pearl millet (Pennisetum americanum (L.) Leeke). Journal of Science Food Agricultural, v.38, p.41-48, 1987.

STRINGHINI, J.H. Utilização do milheto como substituto do milho em rações para codornas japonesas (Coturnix coturnix japonica) em postura. In: CONGRESSO BRASILEIRO DE MEDICINA VETERINÁRIA, 23., 1994, Recife. Anais... Recife: SPEMVE, 1994, p.617.

UNIVERSIDADE FEDERAL DE VIÇOSA - UFV. SAEG Sistema de Análises Estatísticas e Genéticas. Versão 7.1. Viçosa: Universidade Federal de Viçosa, 1997. 150p.

Recebido em: 08/02/02

Aceito em: 26/09/02 